\title{
LA FICCIONALIZACIÓN DE LA VOZ AUTORAL Y SUS EFECTOS EN LA RECEPCIÓN
}

Liliana N. SWIDERSKI

Universidad Nacional de Mar del Plata

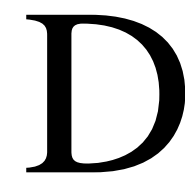
esde mediados del siglo XIX y en la estela abierta por el Romanticismo, es perceptible una creciente problematización de la categoría autoral, íntimamente vinculada con las direcciones especulativas abiertas por la psicología, la filosofía y la sociología acerca de la cuestión del sujeto. Estas indagaciones se apoyaron, en gran medida, en los planteos de Karl Marx, Friedrich Nietzsche y Sigmund Freud: los «maestros de la sospecha» (28) en palabras de Paul Ricoeur, pues los tres han explorado, en sus respectivos campos, las realidades ocultas que constituyen el sustrato de lo manifiesto. Como resume con acierto Juan Lamarche, a partir de estos tres pensadores «la soberanía y autonomía del sujeto comenzó a tambalear» (2).

En el ámbito de la literatura, una de las estrategias más concurridas en relación con esta crisis es la creación de escritores a los que se atribuyen pasajes de la obra, como puede observarse en Rainer Maria Rilke (1875-1926), Valéry Larbaud (18811957), Paul Valéry (1871-1945), T. S. Eliot (1888-1965) y, de manera sobresaliente, en Fernando Pessoa (1888-1935), quien ha desplegado una «galaxia» de setenta y dos personalidades poéticas, más o menos desarrolladas ${ }^{1}$. En el ámbito hispanoamericano, destaca en forma temprana la obra de Antonio Machado (1875-1939) con sus apócrifos Juan de Mairena y Abel Martín; pero también pueden mencionarse los poetas antologados en las Vidas improbables del español Felipe Benítez Reyes (1960-); los heterónimos del argentino Juan Gelman (1930-), como José Galván, Julio Grecco, Yamanokuchi Ando o Sydney West; o los del mexicano José Emilio Pacheco (1939-), entre los que cabe consignar a Julián Hernández y Fernando Tejada.

\footnotetext{
${ }^{1}$ Con una obra profusa y sumamente elaborada, descuellan especialmente el clasicista Ricardo Reis, el vanguardista Álvaro de Campos, el maestro Alberto Caeiro y, finalmente, Bernardo Soares, prosista y autor del Livro do desassossego.
} 
Pero lo que me interesa destacar aquí, especialmente, es que la duplicación (o multiplicación) de la instancia enunciativa tiene vastos y contrastantes efectos en los modos de lectura. Como señala Álvaro Cardoso Gomes: «a partir do primeiro momento em que alguém se desdobra, como que provocando o necessário desdobramento de todos os outros que o lêem» (4). El propósito de este artículo es enunciar algunas de las posibles repercusiones que la diseminación del nombre autoral genera en el lector. Aunque inicialmente he estudiado el fenómeno a partir de las obras de Antonio Machado y de Fernando Pessoa, confío en que estas precisiones puedan ser útiles para el análisis de otros autores que han transitado similares caminos creativos ${ }^{2}$.

En principio, en la obra poética de apócrifos y heterónimos es clara y manifiesta la ruptura de la efusión confesional y el doble cariz de los textos, que invitan al receptor a identificarse con las emociones y experiencias de las personalidades literarias pero que, simultáneamente, rechazan una lectura de este tipo al poner sobre el tapete el carácter artificial de los sujetos de la enunciación. Podríamos decir que, de modo análogo a lo que sucede en el teatro antinaturalista, contemporáneo a la eclosión de los fenómenos estudiados, se busca quebrar «el efecto de realidad» ${ }^{3}$. La heteronimia trastorna así las convenciones de verosimilitud en que la poesía lírica se afianzaba desde el romanticismo: según Regina Zilberman, al ser cada personalidad literaria resultado de una invención consciente y voluntaria, «ela impede que, de antemão, se defina o lirismo desde as noções usuais de confessionalismo e impressão de real» (182). De tal manera, la obra heterónima pone sobre el tapete problemas como el estatuto constructivo del hablante poético, la figuración del tiempo, la verosimilitud de las experiencias expresadas, etc.

Similar mecanismo se produce respecto del ensayo, un género que promueve, como indica Walter Mignolo en «Semantización de la ficción literaria», la identificación entre rol social y rol textual (90): mientras que en todos los géneros narrativos suele realizarse una división entre narrador y autor, en el ensayo -siempre según Mignolo- el rol social en función del cual se escribe y el rol textual del emisor resultan correferenciales. En el caso de los ensayos firmados por personalidades literarias, las mediaciones que sufre la voz de la enunciación parecieran debilitar el principio de autoridad. Por eso, muchas han sido las especulaciones de la crítica en torno al sentido

\footnotetext{
${ }^{2}$ Fruto de esas investigaciones es el libro Antonio Machado y Fernando Pessoa: El gesto ambiguo (sobre apócrifos y heterónimos), Mar del Plata, Martín y EUDEM, 2006.

${ }^{3}$ El concepto de «efecto de realidad» remite al artículo homónimo de Roland Barthes (1968). Hacemos la salvedad de que nuestra atención aquí no se dirige al problema del realismo o del discurso de la historia, sino que se centra principalmente en el «como si» que parece otorgar, a lo que sólo tiene existencia lingüística, una existencia extratextual (48).
} 
(y objetivos) del empleo de máscaras en textos ensayísticos: desde el ocultamiento hasta una pretendida irresponsabilidad respecto de las opiniones vertidas. Sin embargo, a diferencia de lo que sucede con los textos anónimos, debe recordarse que el éxito de la operatoria implica que conozcamos el nombre del sujeto empírico que es el origo del discurso, y por tanto consideramos que las hipótesis antes mencionadas deberían relativizarse. En los ensayos firmados por personalidades literarias, el cuestionamiento del lazo entre autoría y autoridad expresa, a nuestra juicio, una clara posición frente al problema del conocimiento. Por erigir al diálogo, la polifonía y el componente lúdico como principios constructivos, se socavan las actitudes dogmáticas: aquellas en que las opiniones resultan incuestionables en la misma medida en que es irreprochable el nombre de quien las enuncia. Los autores que cultivan la estrategia heteronímica exploran con provecho las posibilidades que ofrece la aparente violación de las convenciones del género ensayístico, cuando simulan quebrar la correferencialidad entre rol social y rol textual a la que recién aludíamos.

Vale la pena recordar que los géneros utilizados están íntimamente vinculados con la figura autoral, a tal punto que el estatuto mismo del autor se define según cuáles cultiva: poeta, dramaturgo, novelista, ensayista. María Teresa Gramuglio, en su excelente artículo «La construcción de la imagen», sostiene que «en cuanto a la trayectoria, es la elección de un género lo que termina por definir las estrategias de escritor» (42). En consecuencia, consideramos que los juegos realizados en uno de los términos que conforman el binomio «autor-género» repercuten, necesariamente, en el otro. Las estrategias que toman como pivote al autor suelen desmontar los límites genéricos, hibridez que incide decididamente en la índole y el diseño de las personalidades literarias: ellas exhiben el juego de la ficcionalización en géneros en los que tradicionalmente estaba oculto (como el lírico) o casi ausente (como el ensayístico). Categorías propias de la novela o del teatro son derivadas hacia el ensayo y la poesía, entre las que cabe subrayar el diseño de personajes, la construcción de secuencias narrativas y el especial empleo del diálogo. El fin último no es el cultivo de una lírica dramática o narrativa, sino la alteración de los «géneros del yo» desde su base, como consecuencia de las alteraciones producidas en el yo mismo ${ }^{4}$. La concepción psicofilosófica que suele animar estas estrategias (la del sujeto como entidad plural) conlleva necesariamente este resultado.

Por otro lado, la mediación de los apócrifos genera un efecto de vacilación a la hora de realizar la atribución de los textos, lo que conduce al lector a tomar diversas posiciones y asumir heterogéneos puntos de vista. En la heteronimia zozobran los

\footnotetext{
${ }^{4}$ Recordemos, por ejemplo, el célebre concepto de «drama em gente» (y no en actos) al que Fernando Pessoa recurre para explicar su heteronimia.
} 
indicadores que, según Michel Foucault, la exégesis tradicionalmente ha aplicado para vincular una obra con un determinado autor: unidad de valor, de estilo, de coherencia conceptual y teórica, de momento histórico (97). El multiperspectivismo, que es considerado como un rasgo fundamental de las producciones literarias que se han catalogado como «posmodernas» (pues debilita la hegemonía de una visión única y autorizada de la historia), se consigue aquí mediante la multiplicación de los observadores, que el autor diseña, justamente, en tanto le permiten tomar distancia de sí mismo. De esta manera, la autorrepresentación autoral se expande y adquiere complejidad a partir del diseño de personajes escritores. En ellos resulta perceptible el enlace con circunstancias variadas del contexto de producción, por lo que actúan como «autoremas» (según un concepto que he acuñado recientemente para articular una metodología de abordaje de las relaciones entre literatura y sociedad) ${ }^{5}$.

El lector se encuentra, entonces, frente a una disyuntiva: puede establecer un vínculo de identificación entre personalidades literarias y autor empírico, pesquisando inclusive la proyección de datos autobiográficos del autor en sus apócrifos; o, por el contrario, puede negar que lo dicho por las personalidades literarias pertenezca al campo de la experiencia y/o de la ideología del autor. En los críticos que abordan el fenómeno también se advierte esta duplicidad en el enfoque. La vacilación constituye una de las principales riquezas de la estrategia, que cuestiona los límites de la identidad y permeabiliza las fronteras entre texto y extratexto, al generar lo que Antonio Sobejano-Morán designó como «violación de los límites ontológicos», mecanismo metaficcional caracterizado por la presencia de un ser en un plano de realidad que no es el suyo -por ejemplo, cuando los personajes dialogan con sus creadores- (28). La imposibilidad para establecer una separación neta entre las distintas voces constituye un

\footnotetext{
${ }^{5}$ Los «autoremas» constituyen los puntos de enlace o nodos entre la poética y la sociedad, explícitamente construidos y formulados en el discurso, que se conectan en forma directa con la figura del autor. En otras palabras: son los «índices de autor» en los que resulta perceptible el enlace con el contexto social. Abarcan tres grupos de estrategias heterogéneas, pero relacionadas a partir de su funcionalidad:

1)La autorrepresentación autoral, que comprende: a) las definiciones y caracterizaciones de «autor» realizadas por un autor determinado; b) los «autobiografemas» que, según el propio productor, tienen consecuencias en su obra; c) las imágenes y contraimágenes de autor presentes en los textos; y d) el diseño de personajes escritores, sea que intervengan en las obras o que las firmen (apócrifos, heterónimos, etc.).

2)El diseño de una figura de lector específica que refluye sobre el estatuto de autor propuesto. Se incluyen aquí: a) las definiciones y caracterizaciones de «lector» y «lectura» elaboradas por el autor; b) las imágenes y contraimágenes de lector diseñadas en los textos; c) las reflexiones del autor respecto de la divulgación de lo escrito (objetivos de la publicación, circuitos, soportes, censura, etc.).

3)La formulación de «cláusulas programáticas», es decir, sentencias o frases que manifiestan opiniones del autor con incidencia en su programa de escritura, que operan como hipótesis de base para su ideario y están ligadas a propuestas de acción (muchas veces, a modo de lemas o slogans).

El desarrollo del concepto se encuentra en el libro de mi autoría Pessoa y Antonio Machado: autores en tensión. Los «autoremas» como enlaces entre literatura y sociedad, Mar del Plata, EUDEM, 2012, pp. 39 y ss.
} 
dilema que ni los escritores mismos están en condiciones de resolver, como frecuentemente se desprende de sus textos metapoéticos.

Nos encontramos, en términos que Paul de Man diseñó en función de sus estudios sobre autobiografía, en el ámbito de lo «indecidible», pues la estrategia nos somete a una polaridad «o/o» (114) que no logramos ni deseamos zanjar: es imposible afirmar la total identificación entre el autor y sus criaturas; pero es imposible, también, declarar su absoluta autonomía. Es claro que las personalidades literarias no son el autor en su persona; no obstante, tampoco resultan completamente ajenas a él. Ideal para caracterizarlas nos parece el concepto de «metaphors of self», que James Olney perfiló para trabajar con los géneros de la literatura íntima:

The self expresses itself by the metaphors it creates and projects, and we know it by those metaphors; but it did not exist as it now does and as it now is before creating its metaphors. We do not see or touch the self, but we do see and touch its metaphors: and thus we «know» the self, activity or agent, represented in the metaphor and the metaphorizing (34).

Pues bien: considero que las personalidades literarias guardan con el autor una relación análoga a la que existe entre un concepto y su metáfora, pues existen algunas características comunes que permiten la asimilación de los dos significantes (es decir, el nombre del autor y el de su apócrifo), pero también hay un exceso, un plus de productividad semántica que obstaculiza su total identificación.

Las reflexiones del Grupo $\mu$ resultan muy útiles para considerar la cuestión, y por eso nos demoraremos en ellas. En su libro Retórica general, se propone que la metáfora «resulta de la conjunción de dos operaciones de base: adición y supresión de semas», por lo que puede definirse como «el producto de dos sinécdoques» que se «intersectan». Es decir que hay «una parte común», «necesaria como base probante para fundamentar la identidad pretendida», y una «parte no común» que «no es menos indispensable para crear la originalidad de la imagen y desencadenar el mecanismo de reducción» (176). Dicho en otras palabras, «la metáfora extrapola, se basa en una identidad real manifestada por la intersección de dos términos para afirmar la identidad de los términos enteros. Y a la reunión de los dos términos confiere una propiedad que pertenece sólo a su intersección» (178). Considero que con los poetas y sus personalidades literarias acontece exactamente lo mismo: hay un plano común que permite identificar los dos significantes, pero también hay sectores distintivos de cada uno. ¿Cómo saber hasta dónde se extiende el terreno común y cuándo comienza la «zona de exclusión»? Al igual que en el caso de la metáfora, «cada lector puede tener su representación personal» (177): es el receptor quien «elabora sin tardar fragmentos de representación según el modelo del árbol o de la pirámide, y busca a qué nivel puede aceptarse la equivalencia de los significados» (177), porque 
cuando consideramos dos objetos, por diferentes que sean, es siempre posible, al recorrer la pirámide de las clases encadenadas, encontrar una clase límite tal que los dos objetos figuren juntamente, pero que estén separados en todas las clases inferiores (177).

Lo usual en el caso de heterónimos y apócrifos es detenerse allí donde es perceptible una flagrante incompatibilidad con el autor en su nombre, y cuando las discrepancias no se han planteado o directamente no disponemos de información alguna, suele asignarse a los dos términos (personalidad literaria/autor) las propiedades de ambos, aun las que sólo pertenecen a su intersección. Como es evidente, no hemos podido escapar de la indeterminación (ni deberíamos hacerlo), pero la comparación de las operatorias con las metáforas nos ha permitido, al menos, encontrar un símil con un elemento debidamente estudiado ${ }^{6}$. Lo que debe recordarse siempre es que el yo de los poetas no se identifica completamente con ninguna de sus metafóricas personalidades literarias, sino que se inscribe en el punto de fuga de esa pluralidad significante. Al respecto, vienen a la memoria las reflexiones de Georges Gusdorf referidas al autorretrato:

El catálogo de Bredius da cuenta de 62 autorretratos, tenidos todos por auténticos, que Rembrandt pintó a lo largo de su vida. Esta tentativa repetida muestra que el pintor nunca quedó satisfecho: no reconocía ninguna imagen como su imagen definitiva. El retrato total de Rembrandt se encuentra en el punto de fuga de todos sus rostros diferentes, de los cuales sería, de alguna manera, el denominador común (12).

Sin embargo, más allá de la vacilación como efecto esperado de lectura, la valoración de las estrategias de pluralización del yo demanda, paradójicamente, que el receptor sea consciente de la presencia unitaria del autor empírico por detrás de sus personalidades literarias. Este fenómeno es similar al que describe María del Carmen Bobes en relación con la semiótica teatral:

La unidad de sentido de la obra procede del autor único, pero también del receptor único que se mantenga desde el principio al final y que relacione los signos, presentados en forma discontinua y en una sucesión determinada, en un signo global, de referencias internas, autónomo, único (119-120).

En tal sentido, es sugerente observar que, a pesar de la diseminación de la voz, que podría ser vista como un gesto trasgresor y vanguardista, las estrategias fuerzan al lector a aproximarse a la obra como una totalidad. Es muy difícil, prácticamente imposible, captar la operatoria heteronímica a partir de poemas o ensayos aislados: en ese caso, sin la confrontación entre las voces (de las personalidades literarias entre sí, o

\footnotetext{
${ }^{6}$ La duplicidad de sentidos en un mismo nombre puede asociarse también con una figura sumamente próxima a la metáfora: nos referimos a la «silepsis», en la que una misma palabra es empleada a la vez en sentido propio y en sentido figurado (Le Guern, 123). En nuestro caso, el nombre del heterónimo evoca, en sentido propio, a un ser de ficción, y en sentido figurado, a un autor cuya existencia es socialmente verificable.
} 
al menos, de las personalidades literarias con el autor en su persona), nos mantendríamos en el ámbito de la pseudonimia. Por eso es pertinente recordar aquí la distinción que Peter Bürger establece entre obra orgánica e inorgánica:

La obra orgánica pretende una impresión global. Sus momentos concretos, que sólo tienen sentido en conexión con la totalidad de la obra, remiten siempre, al observarlos por separado, a esa totalidad. Los momentos concretos de la obra de vanguardia tienen, en cambio, un elevado grado de independencia y pueden ser leídos e interpretados tanto en conjunto como por separado, sin necesidad de contemplar el todo de la obra. En la obra de arte de vanguardia sólo puede hablarse en sentido restringido de «totalidad de la obra» como suma de la totalidad de los posibles sentidos (183, la cursiva es mía).

Por eso, y retomando el concepto de «contrato» que Philippe Lejeune acuñó para el pacto autobiográfico y que Gerard Genette adaptó al pastiche, creemos que se hace necesario hablar aquí de un «contrato de heteronimia», pues sin él sería imposible leer la operatoria. Este contrato, como el que describe Genette, puede ser tácito (1989: 157), aunque sin duda el escritor mismo quiere ponerlo en evidencia:

[...] lo más frecuente es que los autores del pastiche, legítimamente interesados en producir su efecto, lo prevengan advirtiendo a su público. Es el contrato de pastiche, del que hablaremos, y cuya redacción es siempre una variante de esta fórmula expresa: esto es un texto en el que $X$ imita a $Y(105)$.

Tanto en heterónimos como en apócrifos el autor también espera que reconozcamos la estrategia, preservándose así, si se nos permite el juego de palabras, la autoridad del autor. El contrato de heteronimia puede expresarse, entonces, como: «este es un texto de $\mathrm{x}$ que debe ser atribuido a y». Tal procedimiento nos enfrenta, no con un texto mentiroso, sino con uno que juega a serlo. El discurso «mendaz» depende, para su eficacia, de la imagen que se ha formado el alocutor de su alocutario, a base de la cual construye su estrategia:

[...] el problema del discurso mendaz es singular: exige la «focalización», al mismo tiempo que se procesa, sobre el rasgo mismo de la mendacidad del contenido (el sujeto hablante sabe que está mintiendo y ha de ir acompasando su discurso de forma que la mentira de él no sea notada) (Castilla del Pino, 1989: 12).

En el caso de las personalidades literarias, en cambio, la focalización en la «mendacidad» del contenido debe ser llevada a cabo tanto por el hablante como por el oyente, porque ambos suscribieron el contrato. Entonces la palabra se vuelve «bivocal», pero no en la acepción de Bajtín -donde el mensaje está preñado de su opuesto o al menos de un desvío respecto de él-, sino en el sentido de que el autor «lleva en sí» otros escritores. No hay una voz que afirme y otra que niegue el contenido de lo enunciado, como en la parodia, sino una voz que atribuye y otra que no atribuye el contenido de lo enunciado a una determinada instancia discursiva. Sin embargo, ello también repercute sobre el mensaje, que debe ser leído en diálogo con la obra total de cada una de las 
voces que confluyen. Nos atrevemos a sugerir, incluso, que el término «bivocal» resulta, etimológicamente, más conveniente para este caso, en el que la duplicación afecta, lisa y llanamente, a la voz o instancia enunciativa. Si tomamos el modelo de los factores y funciones del lenguaje de Jakobson (32 y ss.), podemos afirmar que la bifurcación no hace aquí al mensaje, sino a su emisor.

Una de las consecuencias inmediatas de tal práctica es que el autor pierde su «integridad». En términos de Catherine Kerbrat-Orecchione: «lo que importa al lector no es que el "yo" represente "honestamente" al autor, sino que en cada una de sus figuraciones [...] se pueda correlacionar la forma lingüística con un referente coherente» (86). Pues bien, la duplicación de la figura autoral viene a generar dos efectos distintos, pues si es verdad que heterónimos y apócrifos resultan figuraciones coherentes, también es cierto que se rompen los enlaces entre cada uno de esos discursos y la voz del autor. El «referente» de Kerbrat se pluraliza, cada heterónimo ha construido un sistema relativamente autárquico y lo ha hecho en el plano sincrónico (y hacemos hincapié en ello para diferenciarlo de la evolución de la obra de cualquier artista, donde quizás sea posible encontrar, con el paso del tiempo, distintas «figuraciones»).

Las personalidades literarias, por añadidura, no sólo ficcionalizan el rol del autor sino también el del lector, que se inmiscuye así en el corazón de la figura autoral. Gracias a ellas, el autor toma distancia de sí mismo e intenta convertirse en su propio «lector ideal», en el sentido que da al concepto Wolfang Iser:

[...] un lector ideal debería poseer el mismo código que el autor. [...] En qué escasa medida el autor es su propio lector ideal, lo atestiguan las expresiones de carácter discursivo de los autores acerca de sus textos. Pues como «lectores» de sus propios textos, por regla general, los autores no reciben su efecto, si no se expresan en discursos, definidos en sus características, acerca de la intención, estrategia y organización de los textos, es decir, la mayoría de las veces en condiciones que tienen valor para el público que debe orientarse según esas expresiones. Pero con este hecho el autor cambia su código y se hace «lector», en condiciones que él como autor del texto ciertamente habría declarado invalidadas. Consecuentemente, para él mismo, por principio, es superflua la duplicidad de autor y lector ideal, aunque sería el único que podría cumplir este postulado (57).

Estas «ficciones de autor» que son las personalidades literarias acaban por convertirse en «ficciones de lector»; no necesariamente porque los poetas escenifiquen o tematicen situaciones de lectura, sino porque la asunción de otra personalidad les permite contemplar su escritura desde una posición excéntrica, mientras que a la vez detentan el privilegio de comprender, como nadie, el código que la anima. El autor habla de sí a partir de sus criaturas y, de ese modo, las estrategias posibilitan que gran parte de las reflexiones del artista sobre su obra no se expresen en el metalenguaje de la 
crítica, pues se ubican en el nivel de la obra misma. La interpretación y comentario de la propia escritura se realiza mediante la multiplicación de los niveles de ficcionalidad.

En síntesis: la creación de poetas apócrifos genera variados efectos en el receptor, que enumeraré muy brevemente. Como uno de los corolarios más evidentes, la exposición del artificio de escritura rompe con la noción lírica de efusión confesional y/o con la correferencialidad entre rol social y rol textual propia del ensayo.

Resulta imposible demarcar los límites en lo referido a la atribución: su estatuto indecidible, deliberadamente provocado, genera uno de los pilares de la estrategia: la vacilación. La postulación (tácita o explícita) de un «contrato de heteronimia» implica que tanto el autor como el lector aceptan la supuesta mendacidad de la atribución, y juegan a ignorarla.

Una posible vía de lectura consiste en considerar el nombre de cada personalidad literaria como metáfora del nombre propio del autor, en tanto existe una base común que permite la identificación entre ambos, pero también un «excedente» de sentido que los diferencia en forma neta: es el lector quien establece en cada caso hasta dónde llega la correspondencia entre los dos significantes.

Debe destacarse el hecho de que una producción fragmentaria y diseminada requiera, paradójicamente, una lectura que contemple la obra como totalidad orgánica, pues sólo esta visión integral posibilita la captación de la estrategia. Finalmente, las personalidades literarias operan como «lectores ideales», pues el autor interpreta su propia obra desde una posición que pretende ajena a sí mismo, y sin necesidad de recurrir al metalenguaje de la crítica.

\section{Bibliografía citada}

BAJTíN, Mijail (1929): Problemas de la poética de Dostoievski. Trad. de Tatiana Bubnova. México, Fondo de Cultura Económica, 1986.

BARTHES, Roland (1968): «El efecto de realidad», en AA. VV., Lo verosímil. Trad. de Beatriz Dorriots. Buenos Aires, Tiempo contemporáneo, pp. 95-101.

BOBES, María del Carmen (1991): Semiología de la obra dramática. Madrid, Taurus.

BÜRGER, Peter (1987): Teoría de la vanguardia. Trad. de Jorge García. Barcelona, Península.

CASTILLA DEL PINO, Carlos, comp. (1989): El discurso de la mentira. Madrid, Alianza. 
DE MAN, Paul (1979): «La autobiografía como desfiguración». Trad. de Ángel G. Loureiro. Suplementos Anthropos 29: «La autobiografía y sus problemas teóricos», 1991, pp. 113-118.

FOUCAULT, Michel (1989): «¿Qué es un autor?». Trad. de Hugo Savino, Revista Conjetural 1, agosto, pp. $87-111$.

GENETTE, Gerard (1962): Palimpsestos. La literatura en segundo grado. Trad. de Celia Fernández Prieto. Madrid, Taurus, 1989.

GOMES, Álvaro Cardoso (1987): Fernando Pessoa: as muitas águas de um rio. São Paulo, Pioneira, Editora da Universidade de São Paulo.

GRAMUGLIO, María Teresa (1992): «La construcción de la imagen», en Tizón, Héctor; Rabanal, Rodolfo; Gramuglio, María Teresa, La escritura argentina. Santa Fe, Universidad Nacional del Litoral, Ediciones de la Cortada, pp. 36-54.

GRUPO $\mu$ (1982): Retórica general. Trad. de J. Victorio. Barcelona, Paidós, 1987.

GUSDORF, Georges (1948): «Condiciones y límites de la autobiografía». Trad. de Ángel G. Loureiro. Suplementos Anthropos 29: «La autobiografía y sus problemas teóricos», 1991, pp. 9-18.

ISER, Wolfang (1976): El acto de leer. Teoría del efecto estético. Trad. de J. A. Gimbernat. Madrid, Taurus, 1987.

JAKOBSON, Roman (1960): Lingüística y Poética. Estudio preliminar de Francisco Abad. Trad. de Ana M. ${ }^{a}$ Gutiérrez-Cabello. Madrid, Cátedra, $2^{\circ}$ ed., 1983.

KERBRAT-ORECCHIONE, Catherine (1980): La enunciación. De la subjetividad en el lenguaje. Trad. de Gladys Anfora y Emma Gregores. Buenos Aires, Hachette, $2^{\mathrm{a}}$ ed., 1997.

LAMARCHE, Juan (2004): «La ficción y la verdad», Cuadernos de la aldea, <http.:// usuarios.lycos.es/clamaga/verficc.html> [última consulta, 24-10-2004].

LE GUERN, Michel (1973): La metáfora y la metonimia. Trad de Augusto de GálvezCañero. Madrid, Cátedra, $3^{a}$ ed., 1980.

LEJEUNE, Philippe (1975): «El pacto autobiográfico». Trad. de Ángel G. Loureiro. Suplementos Anthropos 29: «La autobiografía y sus problemas teóricos», 1991, pp. 47-61.

MIGNOLO, Walter (1980): «Semantización de la ficción literaria», Dispositio VI/1516 , pp. $85-127$.

OLNEY, James (1972): «A theory of autobiography», en Metaphors of Self. The meaning of autobiography. New Jersey, Princeton University Press, pp. 3-50.

RICOEUR, Paul (1965): Freud: una interpretación de la cultura. Trad. de Armando Suárez. México, Siglo XXI, 1970.

SOBEJANO-MORÁN, Antonio (2003): Metaficción española en la posmodernidad. Barcelona, Kassel, Edition Reichenberger. 
Tropelías. Revista de Teoría de la Literatura y Literatura Comparada, 19 (2013) 367

La ficcionalización de la voz autoral y sus efectos en la recepción

SWIDERSKI, Liliana (2006): Antonio Machado y Fernando Pessoa. El gesto ambiguo (sobre apócrifos y heterónimos). Mar del Plata, Martín y EUDEM.

ZILBERMAN, Regina (1996): «Fernando Pessoa e o leitor ideal», Annali - Sezione

Romanza, Instituto Universitario Orientale, Nápoli, Societá Editrice Intercontinentali, pp. 181-192. 